\title{
Parametric Adjustments by Children Acquiring Urdu Language
}

\author{
Fouzia Rehman Khan ${ }^{1}$, Shehnaz Mehboob Baloch ${ }^{1} \&$ Mehwish Ali Khan ${ }^{1}$ \\ ${ }^{1}$ Department of English, Sardar Bahadur Khan Women's University, Quetta, Pakistan \\ Correspondence: Fouzia Rehman Khan, Department of English, Sardar Bahadur Khan Women's University, \\ Quetta, Pakistan. E-mail: fozia.wu@gmail.com
}

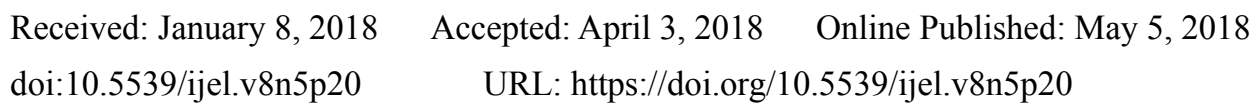

\begin{abstract}
The present research lies in the field of language acquisition. Chomsky's principles and parameters $(1981,1986)$ serve as the theoretical framework for this study. The research takes acquisition of Urdu as a case. The data for the study comprises of common recorded utterances produced by children between the ages of 24-30 months, acquiring Urdu language. The study explores the parametric settings and adjustments in these utterances. The results show that children remained consistent with non-null subject, head last principle while wh fronting was rarely observed in these utterances. Knowledge of the parametric settings can be helpful for the language teachers in predicting difficulties in second language acquisition. It offers a plausible solution to the logical problem of language acquisition.
\end{abstract}

Keywords: SLA, parametric adjustment, principles and parameters, Urdu

\section{Introduction}

The paper is based on Chomsky's notion of Principle and Parameters. According to him there are two aspects of language learning one is the grammar that is called as the universal grammar which is acquired naturally, the other is the one which is different for each language and therefore needs to be learned by the language learner of every language. These are called as Parameters. According to Chomsky $(1981,1986)$ all languages share a basic framework based on a set of Principles. Parameters, on the other hand, capture the notion of variation among languages. In other words principles are somehow controlled by parameters. This is the reason that the basic word order of languages is SVO, SOV, VOS and OVS. The goal of the learner is to choose and learn the correct parameter of the particular language.

Children acquire language with the help of language acquisition device with the faculty that guides them in learning of grammar. This grammar according to Chomsky (1993) is based on Universal Principle. But complete grammar of a language cannot be acquired through these common principles otherwise all natural languages would have a single grammar and no grammar learning would make a part of language learning and as a result language learning would have been restricted to lexical learning only which is not the case. Although there are universal principles that constitute universal grammar (Innate grammar), which provides an outline for all languages, yet there are aspects of grammar that need to be learned by the child. These are the aspects that account for language variations; aspects that differentiate one language from another. In other words, grammatical learning will be limited to parameterised aspects of grammar (that is those aspects of grammar which are subject to parametric variation from one language to another". To determine what aspects of grammar are to be learned by the child it is important to investigate the parametric variations in the grammar of different languages.

Parameter setting was originally conceived as being executed by a triggering mechanism that resided in LAD. Each time the mechanism was engaged for acquiring a language, it had immediate and far-reaching consequences throughout the learner's grammar. A metaphor for this mechanism was that of a switch where the learner simply flicked a switch to one setting or the other in response to some triggering experience that was really observable in the primary linguistic data. The switch metaphor suggested that at some circumscribed period during the course of development, the setting of a parameter would be decisively triggered, with one value being adopted rather than the other (Roeper, 1999).

So the switch metaphor implies that when the child needs to switch from a null subject language to a non-null subject or from wh movement to one without such movement. As a matter of observation in logical argument 
children who are set to set parameters to either of the binary values can misset the parameters too i.e., being initially inconsistent in setting values with the local language. Resetting of parameters can take some time. This mismatch is straightened up with the right kind of data.

The following short study is conducted to analyse the parametric setting of recorded utterances by children acquiring Urdu language between the ages of 24 and 30 months. The study aims at deducing the choice of three parameters from their binarity (a choice between the two) by these children.

The three parameters which occur in binarity for all I- languages, are as follows

1) Head Position parameter (every syntactic structure is a projection of ahead word)

(Radford, 2009, p. 61). The language can be either head first or head last.

2) Wh Subject Parameter (a parameter that determines whether wh expression can be fronted in an interrogative structure or not) (Radford, 2009, p. 12)

3) Null Subject Parameter (whether the language allows finite verbs to have a subject or not) (Radford, 2009, p. 13)

\subsection{Research Questions}

The study is designed to answer the following research question.

Which sort of parametric adjustments are made by children acquiring Urdu language?

\section{Literature Review}

The time period for Language acquisition can be an abundant source of evidence about the learning process that how the target language is acquired and what the child is acquiring. The present results in this field have numerous significant implications. In certain cases it is debatably most essential that what the child learns can be defined as the setting of nonconcrete parameter. It is observed that in such cases diverse grammatical patterns are being affected by unexpected coordinated changes.

In 1986, Hyams in his study on time course of parameter-setting, investigated acquisition of overt and null subjects in Italian and English. In his study, he observed that during acquisition children acquire Italian and English by omitting the matrix subject in their sentences. Her observation proposed for both groups was that the preliminary setting of the Null Subject Parameter chosen is that which permits matrix null subjects, i.e., [+NS]. For English learning children, positive evidence (in the form of overt expletives) would lead children to define that English takes the opposite setting [-NS]. It explains that waged between language in the structure of modals also monitored from different settings on the Null Subject Parameter, as foretold. It was perceived that modals are being used by English language learners only when they terminated using Null subjects.

In the discipline of Acquisition mechanisms a remarkable result is that children are explicitly not engaged with simple trial-and-error learning: if they were, they would automatically commit various commission errors that almost never occur (e.g., Maratsos, 1998). The sign from impulsive speech denotes that children are mostly Deterministic learners (Berwick, 1985), An incorrect grammatical choice is seldom adopted and if it is then learners try to backtrack from it and wait until they comprehend the significant points of the target grammar, before making a productive use of a new grammatical structure.

Meanwhile the child is working underground he would not have any means to express a target idea resourcefully, many things can happen in child's impulsive speech. In few cases the child will adopt a roundabout way to express his ideas and other times the child will describe the intended meaning, omitting the integral segments, about which he is undecided, of the target grammar. Still it can also come about that for a moment a particular meaning is just indescribable. In 2006, Sukiyaki \& Snyder observed longitudinal corpora, opting ten English learning children as a sample of their study and the results declared that six of them had an affected gap between the onset of direct-object queries and the onset of prepositional questions ("P-questions", e.g., "What did you put the box on _?"). For age from 2.2 months to 9.0 months (mean 4.9), these six children were regularly constructing direct-object questions, and also the declarative counterparts to P-questions (i.e., sentences in which the main verb took a PP complement), but were never generating P-questions. Moreover, when P-questions lastly did commence to appear, they were used almost as recurrently as direct-object questions. The outcome that a child can practice a prolonged period of ineffability, followed almost directly by the onset of adult-like production, and has chief inferences for the theory of grammar. Then automatically a proposed grammatical formalism is ruled out, which somehow allows the child to add advanced or new structures incrementally, and lest it allows the child to be self-assured about the selection of grammatical structures even though few grammatical choices remain undecided. 
Focusing on learnability problems Dresher (1998) adopts a very distinct approach, based on the idea of innately quantified "learning path". The main inspiration for this approach is the fact that interdependencies between parameters setting can result into various learnability problems. The reduction of these problems is possible if the target learner recognizes the enumerate setting of parameters. Possibly, the problems can be eradicated all in all if the learner correctly recognizes what to look for, at each probable point in the path; and knows where to go next, depending on the outcome. Dresher's main concentration was on how a child could possibly recognize the exact setting for a set of main parameters of metrical phonology. His aim was to make the learner understand which parameter is to set first, and to deliver a procedure which the learner can practice to recognize the exact and correct value of that parameter. Depending on the answer, the learner was directed to another parameter to tackle next, and provided with a procedure to follow.

Another research was conducted under the assumptions of Chomsky's UG and parameter setting (Gavarró, Leela, Rizzi, \& Franck, 2015), in which the man focus was on acquisition of word order in Hindi/Urdu and Malayalam. An experiment was conducted on acquisition of OV order on nineteen months old in fact, with first Urdu/Hindi as their first language. The test was a combination of the weird-word-order paradigm, preferential looking mode and pseudoverbs. The results were concluded that infants below the age of 19 months could identify (parsed) the SOV grammatical order, that indicated that the parameter responsible for the OV order was set at 19 months of age.

There has been some work on word order parameter to investigate how the surface word orders have a relationship with the deeper structures and how these deeper structures are parameterized that result in the cross linguistic variation in the word order that are visible. Some of the investigators of word order related parameters are Travis (1984), Koopman (1983) and Nyberg (1987).

Some of the other researchers have worked on the existence of null subject in child language and to differentiate true null subject languages and non null subject languages (Hyams, 1986; Kazman, 1988). The work on parameters has also been done on learning of second language (Flymn, 1987; Phinny, 1987; Archibald, 1990).

The output that is produced by the child also depends on the kind of input that is provided. There are two kinds of evidences in this regard. One is the positive evidence that refers to the grammatical sentences; the other is the negative evidence consisting of ungrammatical sentences and performance errors. According to Nyberg (1992) the language-learning environment does not always contain positive evidence; it is the learner to determine the filter out items according to the parametric settings. Also Child's own utterances may act as a feedback for his learning but the popular assumption is that the child lacks any consistent information about his correctness at least of his early utterances. Brown et al. (1969) believe that the corrections made by the adults can be useful but oftentimes are found to be misleading. Nyberg (1992) found that the child did not detect the negative evidence in the input data because he had a reliable access to correctness therefore it can be hypothesized that all inputs that the child receives are considered grammatical by the learner.

Chomsky's position (1993) of principles and parametric settings has remained dominant and a popular one among the generative grammarians with regard to linguistic theory and its overall structure. His notion can be summarized as the principles of UG have parametric setting that becomes the differentiating ground for different languages.

Smith \& Law (2009) investigated the characterization of parametric variation and have suggested at least seven identity criteria for such variation. These criteria include cognitive, representative, systematicity, dependence on input, determinism, discretion, mutual exclusiveness and irreversibility. They call these parameters as "switches as on or off" (p. 33) for particular linguistic properties. Parameters make the task of language acquisition easier as the child only needs to set the value of the parameters according to the stimuli he is exposed to. Parameters reduced the range of possibilities, making the language acquisition task simple. According to Chomsky (2006) "acquisition is a matter of parametric setting, and is therefore divorced entirely... from the principles of UG." (p.183). This means that selection rather than instructions are more important in language acquisition.

Niyogi \& Berwick (1996) studied parameters mathematically so as to calculate the number of positive examples or evidences to reach the target grammar. This may enable us to actually quantify the data needed to learn a language. He also used the term language and grammar interchangeably.

The missetting of parameter was investigated by Hyams (1986) when he found the English-speaking children skipping overt subject and producing a pro drop parameter. It is this non null subject parameter that distinguishes English from other null subject languages such as Italian. But studies by other researchers as Thomton (1990), Becker (2000) and Armon et al. (2004) show through their empirical data that finally every child's grammar converges to adult use of the local language, which means that parametric resetting is responsive to the input. 


\section{Delimitations}

The phonetic aspect is being ignored here and only syntactic structure of the phrases is taken into consideration. A corrected adult counterpart for each utterance is also given, to have an idea of actual syntactic structures of the language, to look for any syntactic deviations in the speech of the child.

\section{Theoretical Framework}

The analysis of this study is guided by Chomsky's theory of Principles and Parameters (PPT) given in the 1980s. Parameters along with Principles form a framework in Generative Grammar as given by Chomsky. Parameters are the switches that can be either turned off or on for a particular language, whereas Principles are the rules of Universal Grammar. In other words Principles are general and Parameters are specific. This framework of Principle and parameters remained popular over the years and many of the linguist have worked within this framework.

Two formal mechanisms that work in this framework are the finite Principles common to all languages and finite Parameters that vary from one language to another but systematically. The common Principles and systematically varied Parameters together form Universal Grammar. Generative grammar is refined each time a language is analyzed through the theory of Principles and Parameters.

Chomsky has given three factors that are involved in language acquisition if it is seen through the biolinguistic perspective. The first one is the genetic endowment, which may be called as Universal Grammar. Second is the experience or the external $\mathrm{E}$ language in the form of language input and third is the principle unspecific to the human faculty of language that is minimalism that account for the variation in languages and is different from Universal Grammar (Richard, 2008).

\section{Data Presentation}

This short research has tried to find out the parametric setting in Urdu language for which the data is collected from 24 to 30 months old children acquiring Urdu language. The data is presented in two columns. One is what the child uttered, and the other consists of corrected adult utterances to understand the proper construction of sentences in Urdu language. Some sentences are given in two ways because such sentences can be correctly said in either of the ways. Mispronunciation of the child is not taken into consideration, since the concern of the present work is syntax alone.

\begin{tabular}{lll}
\hline & Child Sentence & Complete Adult Sentence \\
\hline 1 & Bhai maara & Bhai nay maara \\
2 & Mama panee & Mama panee chaye \\
3 & Darwaza kholo & Darwaza kholo \\
4 & GaRee jana & GaRee mein jana hey \\
5 & Mama neend aye & Mama neend a rahee hey \\
6 & Bili maoin baghee & Billi bhagee \\
7 & Gir gaya & Gir gaya \\
8 & Bahar jana hey & Mujay bahar jana hey \\
9 & Chacha pass jana hey & Mujay chacha k pass jana hey \\
10 & Api toffee lae & Api toffee lae hey \\
11 & Kaila khana & Mujay kaila khana hey \\
12 & Mama khana & Mama khana dein \\
13 & Kya howa & Kya howa \\
14 & Mama dey du & Mama dey du \\
15 & choRe du & choRe du \\
\hline
\end{tabular}

\section{Data Analysis}

1) In "Bhai Maara" "marra" is a verb "Bhai" is the subject, which is overtly present, while complement is absent which was supposed to be "mujay". In adult version the sentence can be said in two ways, either "mujay Bhai nay maara" or "bhai nay mujay maara". Urdu is known to be SOV structured language. Considering the child utterance again, in the first case it can be the case of truncated object while in the second its non-null subject. Looking at the headedness principle, the phrase as uttered by the child is head last.

2) In "mama pane" both words are nouns, the main verb is missing which is perhaps supplied by the expressions of the child. Mama is the address form and a noun, panee is the complement/object. If we look at the 
adult construction "Mama panee chaye", verb "chaye" comes in the end. "mujay" is the subject missing in the baby's utterance, but it is not incorrect if it is missing from a proper utterance as "mujay panee chaye" it can be "panee chaye" then it can be the case of imperative null subject. Head last principle is selected as sentence is basically the projection of the verb, and the verb occurs at the end of phrase.

3) In "darwaza kholo", "kholo" is the verb, and "darwaza" is the complement. Subject is covert and imperative null subject is observed. Head last parameter is followed, as the verb follows the complement. Even if "tum" is added before the object, it would be an address term or a deictic expression and not a subject in either case.

4) In "billi maoin bhagee" "bhagee" is a verb, which has one subject with two expressions, one is the word used by the adults second one is usually used by children. Non-null subject parameter is adjusted and the phrase shows head last principle.

5) In "gaRee jana" "jana" is the verb and "gaRee" is the complement. In the corrected adult counterpart the complete sentence is "mujay gaRee mein jana hey" null subject truncation is done by the child. The preposition is also missing. Head last principle is followed.

6) In "mama neend aye" "aye" is a verb and mama is the address term, "neend" is the complement. In its full sentence form "mama mujay neend a rahee hey" "mujay" is a truncated non-null subject. The phrase is head last.

7) In "gir gaya" gir gaya is a verb, The phrase lacks any form of subject or a complement. To analyse such an utterance it is important to look at some of the options to a complete subject. If the complete version is "panee gir gaya" "Panee" is the object. There is no overt or covert subject neither in the adult counterpart of the phrase nor in the possible completion of it. Here null subject parameter is followed.

8) In "bahar jana hey" "jana hey" is a verb, bahar is complement. In its complete form the sentence could be "mujay bahar jana hey" therefore non-null truncated subject parameter is followed. The phrase is head last, as verb follows the complement

9) In Chacha pass jana, jana is verb, chacha is the complement, "pass" is a part of preposition. Seeing its adult counterpart, the utterance can be said as "mujay chacha k pass jana hey", non null truncated subject is adjusted. The phrase has a head last structure.

10) In "api toffee lae", lae is verb, api is its subject and toffee is the complement. It's a complete utterance, following the structure SOV. Non-null parameter is visible. The phrase is head last.

11) In "kaila khana" Khana is the verb, Kaila is the complement. Non null subject parameter is chosen, as "mujay" as subject is missing but understood. Verb follows the complement, so the phrase has a head last structure.

12) In "mama khana dein" dein is the verb, mama is the address term and khana is the complement. Non-null subject adjustment can be observed as "mujay" is understood and acts as a pro and can be said to be imperative non-null parameter.

13) In "Kya howa" Wh is placed initially, therefore wh fronting is opted in wh movement parameter.

14) In "Mama dey du", dey du is a verb and mama is the address term. Both subject and object are not uttered. Looking at the adult counterpart, the sentence can be "mama mujay dey $d u$ ", therefore non null subject in the form of imperative is followed. The phrase has a head last parametric setting.

15) In "Chore $d u$ ", there is just a verb with an imperative non null subject. This short phrase in a counterpart adult utterance can be said in two ways. One is "Mujay chore du" other can be "chore du mujay". In the first structure complement comes before the verb and it depicts the phrase as head last. In the second one complement follows the verb, making it appear head first.

\section{Conclusion}

Looking at the above data, in most of the sentences, subject is missing but sometimes these sentences are imperative for instance in sentence mama panee chayee, bahar jana hey and mama khana dein, which allow null subject as in English. Then in many of the sentences there are truncated null subjects for example in sentence Bhai mara, gaRee jana, mama neend aye, bahar jana hey, chacha pass jana hey, kaila khana, mama khana dein. Due to the presence of imperatives, self understood subjects and truncated null subjects we cannot say that Urdu is null subject language. Moreover, the data also reveals that the child when specifying himself as a subject often omits it, perhaps accommodates it with his body language especially during the early stages of language acquisition. The child remained consistent with non null subject parameter in almost all the utterances. 
If Urdu is a head first language then the child should properly place the complement of a verb after a verb and of preposition after a preposition. In the sentences "darwaza kholo", bahar jana hey, kaila khana hey, api toffee lae hey, this is not found to be the case, so according to a part of this data Urdu can be head last language. The child showed consistence in following the head last principle in headedness.

There is only one example of Wh sentence where the child puts it in the front, so Urdu seems to be wh fronting language like English. It can also be seen from the utterances that prepositions are consistently missing. There is not even a single utterance of the child with any preposition. Nouns are always present, verbs mostly except in "mama pane" and preposition never. Most of the time the subject is the child himself, which he seldom utters but it is PRO and self understood. Many of the uttered phrases which are a combination of a noun and a verb, verb is found to be following the noun and not wise versa though there might be a possibility in adult utterances for instance "darvaza kholo" and "kholo darwaza", but such instances are rear.

An overall regularity is observed in parametric adjustment of the three parameters, by children acquiring Urdu language as indicated in the data collected. In other words, no major deviation is noticed.

\section{Implications}

The parametric differences between languages explain the difficulty in second language acquisition such as L1 transfer; incompleteness but parametric variations cannot clearly explain variability among different learners with different L1s. Knowledge about parametric settings may help language teachers to predict the difficulties of learners, for instance, the problem of null subject for speakers of non null subject languages. It helps in prediction of course of acquisition.

\section{References}

Archibald, J. (1989). Metrical Parameters: A Neglected Area of Research. Boston University Conference on Language Development.

Armon-Lotem, S., Stephen, C., \& Spyridoula, V. (2004). Interface conditions in child language: Cross-linguistic studies on the nature of possession. Language Acquisition, 12(3-4), 171-217. https://doi.org/10.1080/10489223.1995.9671743

Becker, M. (2000). The development of the copula in child English: The lightness of be. Los Angeles, CA: University of California dissertation.

Berwick, R. C. (1985). The Acquisition of Syntactic Knowledge. Cambridge, MA: MIT Press.

Brown, R., Cazden, C. B., \& Bellugi, U. (1969). The Child's Grammar from I to III. In J. P. Hill (Ed.), Minnesota Symposium on Child Psychology (Volume 2). Minneapolis: University of Minnesota Press.

Chomsky, N. (1981). Lectures on Government and Binding. Dordrecht: Foris.

Chomsky, N. (1986). Knowledge of Language: Its Nature, Origin, and Use. New York: Praeger.

Chomsky, N. (1993). Lectures on government and binding: The Pisa lectures (No. 9). Berlin: Walter de Gruyter. https://doi.org/10.1515/9783110884166

Chomsky, N. (2006). Language and Mind (3rd ed.). Cambridge: Cambridge University Press. https://doi.org/10.1017/CBO9780511791222

Dresher, B. E. (1998). Charting the learning path. Linguistic Inquiry, 30, 27-67. https://doi.org/10.1162/002438999553959

Flynn, S. (1987). A Parameter-Setting Model of L2 Acquisition: Experimental Studies in Anaphora. Dordrecht: Reidel. https://doi.org/10.1007/978-94-009-3747-5

Gavarró, A., Leela, M., Rizzi, L., \& Franck, J. (2015). Knowledge of the OV parameter setting at 19 months: Evidence from Hindi-Urdu. Lingua, 154, 27-34. https://doi.org/10.1016/j.lingua.2014.11.001

Hyams, N. (1986). Language Acquisition and the Theory of Parameters. Dordrecht: Reidel. https://doi.org/10.1007/978-94-009-4638-5

Kazman, R. (1988). Null Arguments and the Acquisition of Case and Infl. Paper presented at the 13th Boston University Conference on Language Development, Boston, MA.

Koopman, H. (1983). The Syntax of Verbs: From Verb Movement Rules in the Kru Languages to Universal Grammar. Dordrecht: Foris.

Maratsos, M. (1998). The acquisition of grammar. In D. Kuhn, W. Damon, R. Siegler, \& R. M. Lerner (Eds.), 
Handbook of Child Psychology. Vol. 2, Cognition, Perception, and Language (pp. 421-466). Hoboken, NJ: Wiley.

Newmeyer, F. J. (2004). Against a parameter-setting approach to typological variation. Linguistic Variation Yearbook, 4(1), 181-234.

Niyogi, P., \& Berwick, R. C. (1996). A language learning model for finite parameter spaces. Cognition, 61(1), 161-193. https://doi.org/10.1016/S0010-0277(96)00718-4

Nyberg, E. (1987). Parsing and the Acquisition of Word Order. Proceedings of the Eastern States Conference on Linguistics. Ohio State University, Columbus, OH.

Nyberg, E. H. (1992). A non-deterministic, success-driven model of parameter setting in language acquisition (Doctoral dissertation, Carnegie Mellon University).

Phinney, M. (1987). The Pro-Drop Parameter in Second Language Acquisition. In Roeper \& Williams (Eds.), Parameter Setting. Dordrecht: Reidel. https://doi.org/10.1007/978-94-009-3727-7_10

Radford, A. (2009). Analysing English sentences: A minimalist approach. Cambridge: Cambridge University Press. https://doi.org/10.1017/CBO9780511801617

Roeper, T. (1999). Universal bilingualism. Bilingualism: Language and Cognition, 2(3), $169-186$. https://doi.org/10.1017/S1366728999000310

Smith, N., \& Law, A. (2009). On parametric (and non-parametric) variation. Biolinguistics, 3(4), 332-343.

Sugisaki, K., \& William, S. (2006). Evaluating the variational model of language acquisition. In K. Deen, J. Nomura, B. Schulz, \& B. D. Schwartz (Eds.), The Proceedings of the Inaugural Conference on Generative Approaches to Language Acquisition-North America, Honolulu, HI (vol. 4, pp. 345-352). University of Connecticut Occasional Papers in Linguistics.

Thornton, R. (1990). Adventures in long-distance moving: The acquisition of complex wh-questions. Storrs, CT: University of Connecticut dissertation.

Travis, L. (1984). Parameters and Effects of Word Order Variation. unpublished MIT PhD thesis.

\section{Copyrights}

Copyright for this article is retained by the author(s), with first publication rights granted to the journal.

This is an open-access article distributed under the terms and conditions of the Creative Commons Attribution license (http://creativecommons.org/licenses/by/4.0/). 